\title{
Bioética e o Compromisso com o Ambiente Natural
}

\author{
Aline Elesbão do Nascimento ${ }^{1}$ \\ Ady Luna Leite ${ }^{2}$ \\ Artemísia Carla ${ }^{3}$ \\ Felipe Jos $\hat{e}^{4}$ \\ Karoline Juliana ${ }^{5}$ \\ Thais Maiara Sousa ${ }^{6}$ \\ Thiago Lindoso Costa ${ }^{7}$ \\ Renata Melo ${ }^{8}$ \\ Camila Melo ${ }^{9}$ \\ Pedro Melo ${ }^{10}$
}

DOI 10.20399/P1982-999X.2016v1n3pp04-15

\begin{abstract}
Resumo
Questões ecológicas e éticas são recorrentes nos debates dos últimos tempos. Ambas refletem a crise civilizacional que enfrentamos nos dias de hoje. $\mathrm{O}$ aumento da consciência e preocupação às questões ambientais resultou em discussões políticas internacionais e acordos globais. No atual modelo econômico a natureza recebe o "título" de recurso natural, servindo apenas para alimentar o sistema e satisfazer a demanda, desconsiderando a sua resiliência, sua habilidade de regeneração e sua capacidade produtora de substância de valor econômico. O capitalismo se faz predominante, e com o advento da globalização a moeda, o capital, foi imbuído de ainda mais força no controle sobre a ordem social, regendo a vida das pessoas, aumentando a desigualdade social, originando, posteriormente, as lutas de classes, que persistem nos dias atuais. Ele peca ao desconsiderar os processos ambientais dentro do processo econômico e a globalização atenua o pensamento capitalista da concentração das riquezas e o desconhecimento da outridade. Nossa espécie evoluiu e se libertou das amarras impostas pelas condições ambientais, e involuiu ao passo que desenvolveu um pensamento de posse sobre a natureza e se excluindo dos processos naturais. Torna-se de grande valia, portanto, uma reflexão quanto à bioética e o meio ambiente, a forma como "pensamos a natureza", a consciência da outridade, e o resultado do pensamento contemporâneo sobre estes fatores.
\end{abstract}

\footnotetext{
Abstract

Ecological and ethical issues are recurrent in the debates of recent times. Both reflect the civilisational crisis we face today. The increased awareness and concern to environmental issues has resulted in international policy discussions and global agreements. In the current economic model nature receives the "title" of natural resource, serving only to fuel system and satisfy the demand, disregarding their resilience, their ability of regeneration and its capacity of producing substance of economic value. The

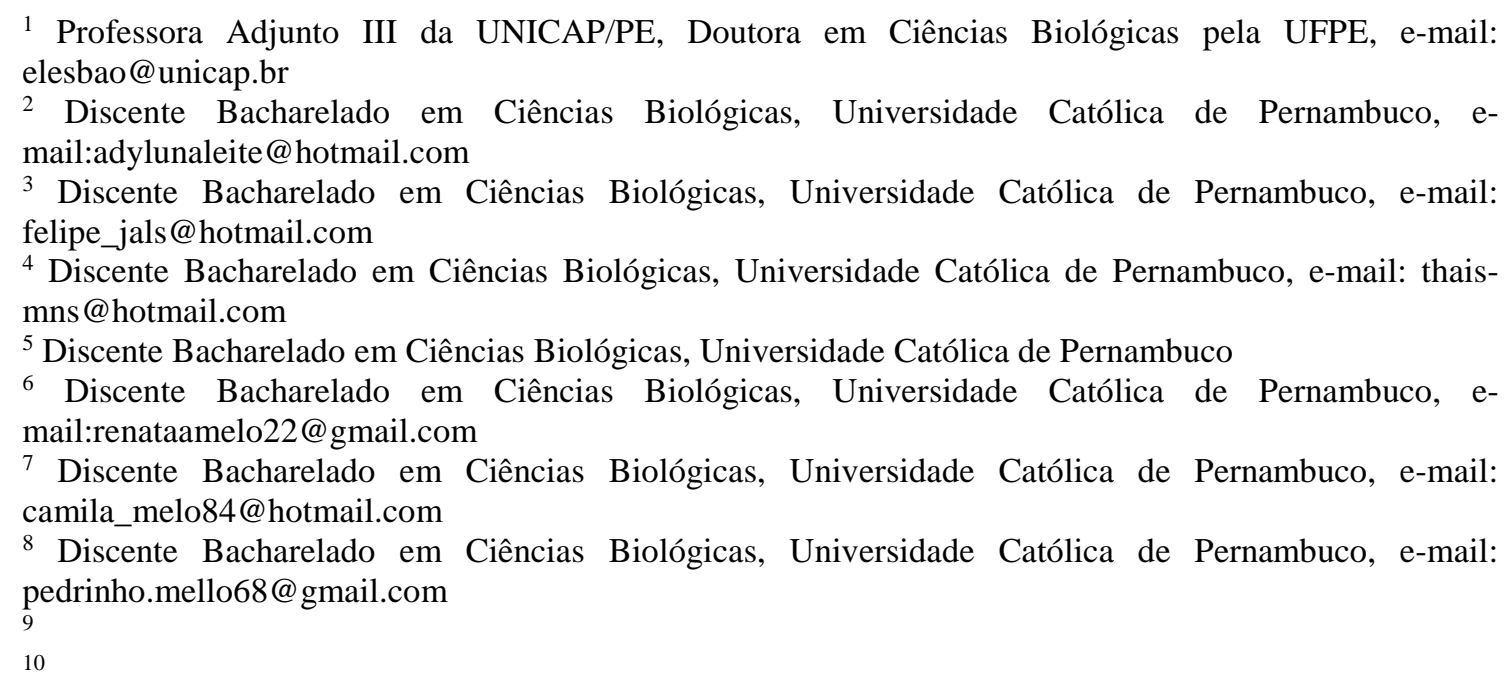


capitalism dominance, and the advent of globalization, capital currency, was imbued with even more force on the control over social order, conducting people's lives, increasing social inequality, resulting in classes fights, that persist today. He suffers to disregard environmental processes within the economic process and globalization mitigates the capitalist thought about the wealth concentration and the ignorance of the alterity. Our specie evolved and released from the bonds imposed by environmental conditions, and involuted by the development of a possession thought about the nature and excluded itself from the natural processes. Becomes very valuable, therefore, a reflection about the ethics and the environment, the way "we think nature", the consciousness of the alterity, and the result of contemporary thought about these factors.

\section{Introdução}

Nos últimos 40 anos, o ascendente progresso científico e tecnológico foi acompanhado do nascimento e evolução de teorias e algumas reflexões que têm como objetivo preservar a humanidade e principalmente o ambiente natural de interferências prejudiciais à sua qualidade de vida. De acordo com Potter (1971), esse conjunto de reflexões gestado e gerado no contexto das descobertas e práticas biotecnológicas e, mais especificamente, biomédicas, tem se feito presente em uma quantidade cada vez maior de áreas de conhecimento, tecnológicas ou não.

É bem verdade que a visão da sociedade humana se voltou para as questões ambientais em tempo recente, metade do século XX. Diversos estudiosos elaboraram artigos, relatórios e estudos associando os efeitos das atividades antropogênicas sobre o ambiente, e mais especificamente sobre a saúde, os quais foram alicerces para a discussão acerca da sustentabilidade e do desenvolvimento sustentável em relação aos efeitos do desenfreado crescimento econômico e industrial (CARSON, 1962; GEORGESCU-ROEGEN, 1971; SCHUMACHER, 1983).

O aumento da consciência e preocupação pelo aquecimento global colocaram as questões ambientais nos principais tópicos das discussões políticas internacionais e nas cláusulas dos acordos globais. A consciência de que a crise ambiental é global, leva à necessidade de respostas planetárias. Nenhum país poderá responder isoladamente aos seus desafios ecológicos. Serão necessários acordos globais, promovidos pelo conjunto das nações, sob a égide da ONU. Entretanto não é possível pensar na questão ecológica isoladamente, ela precisa ser refletida com o problema da ecologia social (GUATARRI, 2001; BOFF, 1996), e com as demais instâncias sociopolíticas, humanistas e bioéticas.

As reflexões sobre o papel do ambiente sobre a existência das sociedades humanas recaem sobre os fundamentos do desenvolvimento sustentável, que envolvem aspectos biológicos, econômicos e sociais. A partir de tais reflexões almeja-se a implantação de mudanças nas condutas humanas, que deverão culminar com transformações nas ordens social, cultural e política das sociedades no século XXI. Há aproximadamente dois séculos, Kant afirmava que na existência da boa vontade, a busca pelo melhor (desenvolvimento sustentável) poderia ser uma lei universal. Mas, o mesmo autor assinala que "muitas vezes o homem, por suas atitudes, inclinações e preferências não têm boa vontade".

Sendo assim, o presente trabalho busca relacionar o entendimento da bioética a cerca das questões ecológicas, sociais e econômicas, chegando a análise de sua interdependência em escala global, enfatizando a relação do homem com o ambiente natural.

\section{Meio ambiente e desenvolvimento humano}


O conceito de ambiente é abrangente e integra componentes diversos, vivos que interagem, trocam, alteram e transformam e abióticos, que dão suporte aos processos biológicos. De acordo com Taylor (1989), o ambiente corresponderia ao chamado mundo natural que:

[...] uma coleção de coisas vivas interrelacionadas ecologicamente que, sem a intrusão ou controle humanos, mantém a existência deles como populações de espécies ao longo do tempo, cada população ocupando seu próprio nicho ambiental e formada por meio dos processos evolucionários de variação genética e seleção natural.

Por outro lado, Passmore e Gardiner (2007) consideram que o meio ambiente natural:

inclui tudo o que afeta a capacidade dos organismos para sobreviver, se reproduzir e prosperar. $\mathrm{O}$ ambiente de um determinado organismo, ou espécies de organismos, incluirá outros organismos. O ambiente de seres humanos pode incluir mosquitos; os seres humanos podem ser parte do ambiente de um mosquito. Para o ser humano mosquitos são uma ameaça; para mosquitos, os seres humanos são tanto uma ameaça quanto um recurso.

Da Declaração da Conferência das Nações Unidas sobre o Meio Ambiente Humano [20]:

Princípio 2: Os recursos naturais da terra incluídos o ar, a água, a terra, a flora e a fauna e especialmente amostras representativas dos ecossistemas naturais devem ser preservados em benefício das gerações presentes e futuras, mediante uma cuidadosa planificação ou ordenamento.

Princípio 4: O homem tem a responsabilidade especial de preservar e administrar judiciosamente o patrimônio da flora e da fauna silvestres e seu habitat, que se encontram atualmente, em grave perigo, devido a uma combinação de fatores adversos. Consequentemente, ao planificar o desenvolvimento econômico deve-se atribuir importância à conservação da natureza, incluídas a flora e a fauna silvestres.

Princípio 5: Os recursos não renováveis da terra devem empregar-se de forma que se evite o perigo de seu futuro esgotamento e se assegure que toda a humanidade compartilhe dos benefícios de sua utilização.

Rangel (2013) afirma que:

A Constituição Federal adotou o princípio do desenvolvimento sustentável, segundo o qual a preservação do meio ambiente ecologicamente equilibrado é necessária à manutenção da capacidade produtiva e à própria sobrevivência do ser humano, implicando no estabelecimento de limites ao exercício das atividades econômicas que geram transformação ou degradação dos recursos naturais. ... A incolumidade do meio ambiente, com realce, não pode ser embaraçada por interesses empresariais nem ficar dependente de motivações de âmago essencialmente econômico, ainda mais quando a atividade econômica, em razão da disciplina constitucional, estiver subordinada 
a um sucedâneo de corolários, notadamente àquele que privilegia a defesa do meio ambiente, o qual abarca o conceito amplo e abrangente de noções atreladas ao meio ambiente em suas múltiplas manifestações, quais sejam: o meio ambiente natural, meio ambiente cultural, meio ambiente artificial e meio ambiente do trabalho (ou laboral).

Os humanos sempre dependeram do meio para a sua sobrevivência e desenvolvimento. O passar do tempo demonstrou que os humanos foram capazes de alterar o ambiente imediato e sofrer sua influência. Desse processo de interação resultou a acumulação de conhecimento e o desenvolvimento de técnicas e tecnologias que facilitariam a escalada humana no globo (BENATAR; DAAR; SINGER, 2003; BENATAR; BROCK, 2011).

Da interação do homem com o seu meio imediato deve nascer uma reflexão acerca de suas relações, contextos e responsabilidades, a partir do que os desenvolvimentos cultural, social e econômico não sejam colocados em lado oposto ao do ambiente natural. A existência humana desde os primórdios esteve associada aos processos ambientais e a outros sistemas vivos, dos quais o humano dependeu, inclusive para o estabelecimento de novos patamares de desenvolvimento (DAWSON, 2013).

A concepção de dependência levou a humanidade a vislumbrar novas formas de relação com o ambiente, incluindo a visão do desenvolvimento sustentável, cujas premissas prescindem desse reconhecimento e de condutas coerentes, vindo a bioética como ferramenta para reforçar a responsabilidade, a precaução, a cautela e o controle das ações humanas em relação do mundo natural que ainda resta (RANGEL, 2013; SCHRAMM, 2014).

\section{A ecologia e as questões bioéticas}

Questões ecológicas e éticas são recorrentes nos debates dos últimos tempos. Ambas refletem a crise civilizacional que enfrentamos nos dias de hoje. Sendo assim, neste tópico, abordaremos as tendências mais relevantes da discussão atual sobre o assunto, promovendo uma reflexão entre as questões bioéticas e a ecologia numa outra perspectiva.

A palavra ecologia, criada por Ernst Haeckel em 1866, consiste no estudo do interretrorelacionamento de todos os sistemas vivos e não vivos entre si com seu meio ambiente. A ecologia, portanto, não pode ser pensada como uma questão isolada, mas necessita de uma reflexão em conjunto com problemas sociais (GUATARRI, 2001; BOFF, 2009), e com as demais instâncias sociopolíticas, bioéticas e humanistas (COSTA, 2013). BOFF (2009) define quatro formas de realização da ecologia: a ecologia ambiental, ecologia social, ecologia mental e a ecologia integral.

Segundo BOFF (2009), a ecologia ambiental visa sempre o meio ambiente, para que não sofra descaracterização, visando à qualidade de vida, à preservação de espécies em extinção e à permanente renovação do equilíbrio dinâmico dos ecossistemas. Entretanto, a ecologia ambiental não vê o homem/mulher e a sociedade como parte da natureza. Ela procura sempre novas tecnologias, menos poluentes, privilegiando soluções técnicas. Assim, busca-se corrigir excessos de voracidade do projeto industrialista mundial, que funciona à base de altos custos ecológicos.

A ecologia social abrange o meio ambiente com o ser humano inserido, bem como nossa sociedade, como partes diferenciadas deste ambiente. Visa não só os valores estéticos da cidade, como melhores praças ou avenidas, mas prioriza saneamento básico, uma boa rede escolar e um serviço de saúde decente, por exemplo. 
Dentro da ecologia social, é importante frisar a injustiça social que, segundo BOFF (2009), é a violência contra ser humano em sua complexidade, sendo este parte e parcela da natureza. Esta se mostra, portanto, como injustiça ecológica contra o todo natural-cultural humano (BOFF, 2009). A ecologia social luta por um desenvolvimento sustentável, que visa atender às carências da sociedade atual e preservar os recursos naturais também para as futuras gerações (BOFF, 2009). BOFF, em Ética da vida:

Mas o tipo de sociedade construída nos últimos 400 anos impede de realizar um desenvolvimento sustentável. Ela é "energívora", montou um modelo de desenvolvimento que pratica sistematicamente a pilhagem dos recursos da Terra e explora a força de trabalho. As forças produtivas e as relações de produção são vistas atualmente como forças destrutivas e relações de produção de desequilíbrios ecológicos desproporcionais. Nos quadros atuais, o desenvolvimento sustentável permanece um desiderato e representa uma negação do atual modelo social de produção.

O tipo de desenvolvimento vigente em nossa sociedade não é universalizável, segundo BOFF (2009), visto a lógica de funcionamento do mercado capitalista que predomina mundialmente. É preciso preocupar-se não só com o bem-estar social, mas com todos os demais seres e o meio ambiente em que estão inseridos.

A ecologia mental, chamada também de ecologia profunda, defende que as causas do déficit da Terra não se encontram apenas no tipo de sociedade atual, mas também no tipo de mentalidade que vigora, cujas raízes remontam a épocas anteriores à história moderna, incluindo a profundidade da vida psíquica humana consciente e inconsciente, pessoal e arquetípica (BOFF, 2009). O antropocentrismo, característico de nossa sociedade, considera os seres não-humanos recursos destinados ao ser humano, disponível sempre que houver a "necessidade" de tais recursos. BOFF descreve tarefas importantes da ecologia mental:

Eis algumas tarefas importantes a que se propõe a ecologia mental: trabalhar numa política de sinergia e numa pedagogia da benevolência, a vigorar em todas as relações sociais, comunitárias e pessoais; favorecer a recuperação do respeito para com todos os seres, especialmente os vivos, pois são muito mais velhos do que nós; e, por fim, propiciar uma visão não materialista e espiritual da natureza que propicie o re-encantamento em face da sua complexidade e veneração diante do mistério do universo.

A ecologia integral, por sua vez, nasce a partir de uma nova visão da Terra, descrita pela primeira vez em 1960, quando lançaram os primeiros foguetes tripulados. Segundo BOFF (2009), da distância em que os astronautas veem a Terra, não existe distinção entre ricos e pobres, ocidentais e orientais. Todos são igualmente humanos. A Terra e os seres humanos emergem como uma única entidade. A ecologia integral tem como objetivo aproximar o homem/mulher a uma visão holística, que é a captação da totalidade orgânica, una e diversa em suas partes, e global (BOFF, 2009), despertandose, assim, a consciência da função do ser humano dentro dessa totalidade. BOFF, em Ética da Vida:

A partir dessa visão verdadeiramente holística (globalizadora), compreendemos melhor o ambiente e a forma de tratá-lo com respeito (ecologia ambiental). Apreendemos as dimensões da sociedade, que 
deve possuir sustentabilidade e ser a expressão da "convivialidade" não só dos humanos, mas de todos os seres entre si (ecologia social).

Uma ética ambiental servirá de elemento de co-existência entre os humanos e o mundo natural não-humano, considerando os impactos que as atividades humanas. Ressalte-se que tais atividades por sua vez, terão consequências para os próprios seres humanos. Daí surge a temática da responsabilidade acerca dos efeitos das ações humanas sobre o ambiente natural. São inquestionáveis as transformações no mundo natural após séculos de exploração e uso irracional e desenfreado. Não mais é possível ignorar que o mundo natural tem seu valor intrínseco distinto de sua exclusiva utilidade (LEOPOLD, 1953). De acordo com a UNESCO (2015):

Bioética é a análise das questões éticas levantadas pela Ciências da vida, a aplicação de políticas de tecnologia, medicina e saúde. Abrange todos os campos do desenvolvimento científico que afetam os seres humanos judicialmente, ambientalmente e socialmente. Criação e compartilhamento de padrões globais, regulamentos e práticas em bioética é crucial. Isto não é apenas para que cada indivíduo possa medir o impacto dos avanços científicos na sua vida e na vida da Comunidade, mas também para que possam contribuir para o desenvolvimento das Ciências da vida e saúde, políticas e tirar proveito de seus benefícios.

A Bioética profunda, criada por Potter em 1998, foi citada pela primeira vez por Peter J. Whitehouse, enquanto aplicava à Bioética o conceito de Ecologia Profunda, de Arne Ness. Esta, por sua vez, já vinha sendo defendida por outros autores como AndréSponville (COSTA, 2013). A ecologia profunda, na visão de Ness, implica propor perguntas profundas às questões complexas que nos envolvem (CAPRA, 1998). Porto e Milanez, em 1984, questionaram o atual sistema econômico, relatando que a emergência e intensificação dos conflitos socioambientais no atual contexto brasileiro e internacional advém de uma visão economicista restrita de desenvolvimento. Esta visão é baseada em critérios de crescimento econômico, sendo vista como única forma de progresso, de natureza produtivista e consumista, agredindo a vida humana e os ecossistemas, assim como seus valores e cultura nos territórios onde os investimentos e as cadeias produtivas se realizam. Sendo assim, a concepção de Ecologia Profunda e da bioética é um desafio, visto atitudes mentais, culturais e sociais (BOFF, 2009).

Por fim, é importante citar a ecologia política e a política ecológica, que contribuem para a compreensão de problemas sociais, de saúde e meio ambiente em suas relações com o processo e os modelos de desenvolvimento da economia de um território, região ou país. Dentro deste contexto, o economista Georgescu-Roegen buscou integrar, entre 1950-1970, os processos econômicos e de organização da natureza, seus fluxos de energia e seus materiais de produção biótica, principalmente através de implicações das leis da termodinâmica no funcionamento da economia (PORTO; MILANEZ, 1984). Uma de suas principais contribuições se refere a crítica do regime energético da sociedade de mercado e industrial, através do uso intensivo de recursos naturais como combustíveis fósseis não-renováveis, acelerando processos entrópicos em uma escala global, exaurindo recursos limitados e comprometendo a reserva das gerações futuras, anulando o desenvolvimento sustentável.

A possibilidade, portanto, de uma economia vinculada à ecologia de forma profunda e sustentável, considerando os recursos limitados da Terra, dependeria da mudança dos padrões de produção e consumo, assim como no regime energético, 
visando formas renováveis com base, por exemplo, na radiação solar, energia eólica e biocombustíveis (PORTO; MILANEZ, 1984).

Essas razões, nos diversos âmbitos do mundo científico nunca foram tão essenciais e necessárias. Enquanto sujeitos éticos é preciso transcender a dimensão superficial dos problemas que envolvem o meio ambiente, visando transformações que a bioética e a ecologia profunda se dispõem a proporcionar.

\section{3. Ética e Economia}

No desenvolvimento da humanidade, a economia surge a partir do momento em que os povos começam a utilizar diferentes formas de produção que exigem diferentes formas de apropriação da natureza. Estes povos, ao passo que se tornam nações, desenvolveram economias de subsistências que, à medida que as sociedades evoluíam para sistemas cada vez mais hierárquicos, geravam excedentes cada vez maiores para classes sociais mais específicas. Foi no desenvolvimento dos transportes navais que se teve início o comércio entre diversas culturas. Este comércio foi incrementado no auge do capitalismo mercantil e, posteriormente, o capitalismo industrial.

Com a generalização do comércio de mercadorias em escala global a ordem econômica tem seu berço, porém esta só é generalizada na esfera social a partir do momento em que é instaurada como lei, fazendo com que a economia começasse a reger a ordem humana.

Com o surgimento da ciência econômica se estabelece uma racionalidade que começa a dominar a ordem natural das coisas do mundo, as formas de produção de riquezas, as regras de intercâmbio de mercadorias e o valor da natureza (LEFF, 2004).

A economia emerge como ciência de classificação racional de recursos escassos e do equilíbrio dos fatores da produção: capital, trabalho e esse fator "residual" - a ciência e a tecnologia - em que se repousa a elevação da produtividade e que se converteu na força produtiva dominante (LEFF, 2004).

Neste modelo econômico a natureza recebe o "título" de recurso natural, servindo apenas para alimentar o sistema e satisfazer a demanda, desconsiderando a sua resiliência, sua habilidade de regeneração e sua capacidade produtora de substância de valor econômico. $\mathrm{O}$ capitalismo se faz predominante, e com o advento da globalização a moeda, o capital, foi imbuído de ainda mais força no controle sobre a ordem social, regendo a vida das pessoas, aumentando a desigualdade social, originando, posteriormente, as lutas de classes, que persistem nos dias atuais.

Atualmente, os humanos enfrentam uma crise ambiental global, decorrente da forma de pensamento da relação do homem com a natureza que é vigente mundialmente. $\mathrm{O}$ modelo econômico neoclássico peca ao desconsiderar os processos ambientais dentro do processo econômico e a globalização atenua o pensamento capitalista da concentração das riquezas e o desconhecimento da outridade. Nossa espécie evoluiu e se libertou das amarras impostas pelas condições ambientais, e involuiu ao passo que desenvolveu um pensamento de posse sobre a natureza e se excluindo dos processos naturais.

Desde muito se fala sobre o uso dos recursos naturais e os impactos ao meio ambiente, porém o trabalho dentro da ciência econômica em busca de um modelo que desse o real valor à natureza em sua relação com a economia, criando um modelo econômico baseado no urso consciente dos "recursos naturais". Nasce a economia ecológica. Entre seus precursores Nicholas Georgescu-Roegen (1971) foi quem desvendou a íntima relação entre economia e natureza, ao definir a relação fundamental que há entre o processo econômico e a segunda lei da termodinâmica. 
O conceito da entropia impõe um limite ao crescimento econômico e à legalidade do mercado, estabelecendo vínculo com as leis da natureza que constituem as condições (físico-biológicas, termodinâmicas e ecológicas) para uma economia sustentável. A entropia mensura o grau de irreversibilidade de um sistema, sendo incorporada ao sistema econômico temos a natureza como matéria prima, de baixa entropia, energia livre para trabalho, e os produtos do trabalho, exossomáticos, de alta entropia, incapazes de serem reutilizados.

A economia ecológica muda o sentido de valor da natureza, deixando de ser abundante, renovável e gratuita, contribuindo à riqueza material de forma inversa, passando da abundância à escassez. Sendo essa inversão de valor justificada através da segunda lei da termodinâmica, que determina que "a entropia total de um sistema termodinâmico isolado tende a aumentar com o tempo, aproximando-se de um valor máximo à medida que as restrições internas ao sistema são removidas".

A grande barreira perante a aplicação de um novo modelo econômico que funcione de maneira complexa e horizontal se faz justamente nos valores e vícios impostos pelo comércio mercantil, desde seu berço, à sociedade e a proporção global que os mesmos tomaram. Como dito, nossa espécie evoluiu, se libertando das amarras impostas pelas condições naturais, porém se encontra hoje sobre a regência da força econômica, adotando uma racionalidade que dispensa a complexidade, que atribui valor a todas as coisas, inclusive à nós próprios. O capitalismo e a globalização controlam a ordem social mundial nessa "regência" da economia, ditando a concorrência sem condições, o mercado sem fronteiras e o lucro sem escrúpulos (ÁVILA, 1998), onde decisiva não é a necessidade vital, mas o maior preço a ser alcançado. É assim que marcha nossa espécie. Adotar um novo modelo econômico significa romper, novamente, amarras impostas. Significa re-evoluir e desenvolver uma racionalidade complexa que abranja as relações ambientais, sociais e econômicas, almejando a perenidade de nossa existência e a equidade nas nossas relações intraespecíficas através do reconhecimento da outridade.

\section{Questões sociais da bioética}

Para entender o aspecto social apresentado na bioética torna se necessário entra um pouco mais no lado social da ecologia, conceituada por Gudynas (1990), como o estudo dos sistemas humanos em interação com os seus temas ambientais. Os principais postulados deste assunto defendem uma interação dinâmica, ou seja, a história dos seres humanos é inseparável da história do seu ambiente e como eles interagem, sendo assim, também é necessário serem estudados juntos, levando em consideração algumas perguntas diante disso; Como os humanos vão utilizar os recursos naturais? Quais tecnologias intensivas serão utilizadas? Como é distribuindo esses recursos? De forma equitativa? Uma distribuição desigual afeta de que maneira a sociedade? Pertencem a discussão da ecologia social a miséria e a pobreza das populações periféricas, a concentração de terras no campo e na cidade, as técnicas agrícolas e agropecuárias, o crescimento populacional e o processo de inchamento das cidades, o comercio de alimento transgênico, o surgimento do buraco de ozônio, efeito estufa, dizimação das florestas tropicais e boreais e etc. (BOFF, 2009).

A ordem do capital hoje mundialmente integrado é profundamente antiecológica, visando um desenvolvimento não sustentável, tendo objetivo de produzir desenvolvimento material ilimitado, explorando pessoas e utilizando os recursos naturais, criando desigualdade entre quem está no mercado e quem não está. As imensas desigualdades no acesso aos recursos - a tudo que caracteriza a qualidade de vida 
tornam esse tema efetivamente orgânico quando se pretende aplicar a ética para garantir a dignidade da vida humana (GARRAFA, 2005).

A injustiça social não é um fenômeno recente, vêm historicamente desde o sistema de escravidão por cor, raça, pensamentos distintos. A parti da "abolição" desse sistema, a situação não mudou muita coisa, os antigos escravos foram libertados, mas sem compensação, logo se instalaram em morros, criando as conhecidas favelas, presente até hoje. Segundo Porto (2009), podemos considera recente o uso dos recursos naturais gerando desigualdade social através de um uso excessivo, sem responsabilidade, que se iniciou na Inglaterra através da revolução industrial, tendo em vista que com exceção dos Maias, nenhuma outra civilização passada, usava os bens naturais de forma devastadoras, citando também que um dos motivos para os Maias serem "extintos", muito se foi por essa forma de pensamento.

O grande problema da revolução industrial, foram as sequelas deixada no meio ambiente, modelos que foram seguidos por outros países do hemisfério norte do planeta, preocupando diversos ambientalista, onde juntos com o fenômeno da globalização foi se expandindo o modelo industrial e capitalista. Diante de toda questão ambiental, uma das sugestões foi o desenvolvimento sustentável, porém, todo voltado para os países subdesenvolvidos (hemisfério sul) não repetirem o exemplo dos localizados no Norte, nesse ponto que entra uma das principais questões da bioética em aspecto social, pois isso acarreta uma grande desigualdade sociais em países, norte e sul do planeta, se assim dividimos.

Considerando a problemática, na última década do século $\mathrm{XX}$, surge uma ferramenta de reflexão, denúncia e busca de alternativas para as situações emergente, para o combate às desigualdades provocadas pela dinâmica imperialista e colonial verificada principalmente nos últimos 60 anos, chamada de bioética de intervenção, mas não se pode confundi a esta forma "colonial" de hoje chamada de colonialidade, sendo definida como a lógica de repressão, opressão, despossessão, racismo", com a época colonial dos franceses, ingleses, espanhóis e portugueses (Garrafa e Porto, 2003). Nos países latinos americanos as imensas desigualdades no acesso aos recursos - a tudo que caracteriza a qualidade de vida tornam esse tema efetivamente orgânico quando se pretende aplicar a ética para garantir a dignidade da vida humana, em função dessa materialização do padrão colonial nos diversos pontos geopolíticos necessita da compreensão e postura ao modos como a colonialidade se instancia nessa região, tendo em vista que no Norte a vulneração econômica está vinculada com outras formas de vulnerabilidade, sendo elas relações raça e gênero, a descolonização da bioética na região sul, deve verificar as conexões entre diversas formas de vulneração social (NASCIMENTO, 2013). Segundo Garrafa (2007) a bioética de intervenção está totalmente ligada ao meio ambiente tendo em vista a superação do paradigma antropocêntrico e a manutenção dos recursos naturais também são preocupações da Bioética de Intervenção. Para isto, seus teóricos apontam que a saúde é intrinsecamente relacionada com as condições ambientais, assim, a concepção do alcance do desenvolvimento deve ser substituída pelo parâmetro da sustentabilidade.

Uma das críticas mais contundentes da Bioética de Intervenção será a respeito sobre como as sociedades de mercado vem produzindo desigualdades econômicas e sociais entre os indivíduos. Esta desigualdade se revela de diversas formas: no macro relações políticas e nas relações pessoais, as quais são 62 perceptíveis na hierarquização dos indivíduos a partir de suas possibilidades ou não na aquisição de bens (GARRAFA, 2006). Segundo Fulgêncio (2013), uma das principais críticas que a Bioética de Intervenção faz em relação à corrente principialista é que esta secundarizou o princípio da justiça em relação aos outros três, principalmente ao destacar o princípio da 
autonomia, fazendo uma escolha deliberada pelo indivíduo em detrimento do coletivo, pelo contrário, trará o protagonismo da justiça social como um dos objetivos a serem alcançados pela bioética. Assim, ao levantar esta questão, esta vertente faz um contraponto ao dizer que o coletivo deve prevalecer sobre o indivíduo.

Leo Pessini (1995), destacou a diferença da bioética feita em países do hemisfério norte e sul, mais especificamente EUA x América latina, onde demonstra uma bioética totalmente voltado as tecnologias e sistema biomédico, como principal discussão da bioética, devido à grande desigualdade social no hemisfério sul é abortado outros aspectos. Um grande número de temas sociais está agora incluído sob o termo de "bioética": saúde pública, saúde ocupacional, controle da população, saúde da mulher, dentre outros. A bioética inclui o bem-estar dos animais de experimentação e preocupações com o meio ambiente. As questões clínicas se ampliaram para incluir temas relacionados com as novas tecnologias reprodutivas conceptivas, os transplantes, a genética, a biologia molecular, entre outros temas. O professor norte americano James Drane fez algumas observações bem interessantes por conta da implementação do Programa regional de Bioética pela OPAS, mostrando diferença de valores sociais:

A tecnologia médica impulsiona o desenvolvimento da bioética clínica. Isto é verdade, tanto na América Latina como na América anglo-saxônica. No início, nos EUA, as perguntas que se faziam com mais frequência tinham a ver com o uso humano de uma nova tecnologia: o uso ou retirada de aparelhos, a aceitação ou recusa do consentimento. Em algumas partes da América Latina, a simples existência de alta tecnologia e centros de cuidado médico ultraespecializados levanta perguntas adicionais acerca da discriminação e injustiça na assistência médica. As indagações difíceis nesta região não são em torno de como se usa a tecnologia médica

O comentário do professor James em 1995 leva em consideração a parte clínica e suas tecnologias, mas podemos levar isso para o meio ambiente também, pois da mesma forma que na américa latina se é pensado em quem terá acesso as tecnologias de saúde, o mesmo acontece com os recursos naturais, sendo uma forma de segrega, um bem que deveria ser de todos e de gerações futuras, como diz o conceito de desenvolvimento sustentável, está em risco por uso de formas erradas, gerando injustiças sociais. Essa posição crítica, a partir da América Latina e, mais precisamente do Brasil, chama atenção para uma realidade muito diferente daquela dos países centrais e aproxima consideravelmente a Bioética de Intervenção dos estudos sobre a colonialidade (NASCIMENTO, 2010). Tais estudos partem de uma posição questionadora dos discursos e práticas hegemônicas e coloniais. Além disso, reivindicam por alternativas epistemológicas que são locais (GROSFOGUEL, 2010).

No período de 20 e 24 de junho, 2005 foi realizada na UNESCO, em Paris, a reunião definitiva de experts dos diversos governos filiados àquela Organização, com o objetivo de definir o teor da futura Declaração Universal de Bioética e Direitos Humanos, chegando a um documento consensual. Dentro desse documento, foram obtidos algumas conquistas em relação a inclusão social, tais como, direitos humanos; respeito pela vulnerabilidade humana e integridade pessoal; igualdade, justiça e equidade; respeito pela diversidade cultural e pluralismo; solidariedade e cooperação; proteção do meio ambiente, biosfera e biodiversidade; responsabilidade social e saúde pública e divisão dos benefícios. Um tópico fala sobre igual e destaca: "Os seres 
humanos, sem distinção, deveriam ser beneficiados pelos mesmos elevados padrões éticos nas pesquisas em medicina e nas ciências da vida" (UNESCO, 2005).

Não há dúvidas de que a implementação da sustentabilidade nos moldes da bioética prescinde dos conhecimentos científicos, do desenvolvimento de tecnologias e da inovação, além de vontade política. $O$ processo requer uma nova visão acerca do relacionamento entre como devemos viver dentro do mundo; como devemos interagir com outros humanos e com o mundo não-humano (VUCETICH; NELSON, 2010).

\section{Considerações finais}

Atualmente, ainda não a incorporação efetiva do desenvolvimento sustentável nas sociedades humanas, o que resulta na inexistência de prioridade para tal processo, estando o humano ainda dependente do lucro máximo em detrimento da qualidade de vida e da qualidade ambiental. A consciência quanto aos problemas ambientais, apesar de sua existência em tempos mais remotos, teve repercussão e influência significativa somente a partir do final do século XX. Pensar de forma interdisciplinar as questões bioéticas, sociais, ecológicas e econômicas se torna, portanto, de extrema importância para a precursão de uma racionalidade ligada intimamente às questões sociais e ambientais, promovendo a justiça ecológica e abrindo caminhos para um envolvimento sustentável. Importante salientar também que para a evolução de uma consciência ecológica interdisciplinar, deve-se antes desenvolver uma consciência humanística e de alteridade, reconhecendo todos os seres vivos como inter-dependentes um do outro.

\section{Referências}

ANJOS, M. F. Introdução. In: Anjos MF, Siqueira JE. Bioética no Brasil: tendências e perspectivas. São Paulo. Sociedade Brasileira de Bioética; 2007.

ÁVILA, F. B. Ética e economia. Universidade Católica de Pernambuco. Recife. 1998. BENATAR, S. R.; DAAR, A. S.; SINGER, P. A. Global health ethics: the rationale for mutual caring. International Affairs, v. 79, p.107-138, 2003.

BENATAR, S. R.; BROCK, G. (eds). Global health and global health ethics. Cambridge University Press, 2011.

BOFF, L. Ecologia: grito da Terra, grito dos pobres. 2 ed. São Paulo: Ática, 1996.

Ecologia: grito da Terra, grito dos pobres. Rio de Janeiro: Record, 2009. Ética da vida. Brasília: Letraviva, 1999.

CAPRA, F. A. A teia da vida. São Paulo: Cultrix, 1998.

CARSON, R. Primavera silenciosa. Madrid: Ed. Trotta S. A., 1962.

COSTA, C.A.S. Biotética e meio ambiente: implicações para uma ética da libertação.

Revbea, Rio Grande, 2013, v. 8, n. 2, p. 31-46.

DAWSON, A. Contextual, social, critical: How we ought to think about the future of bioethics. Bioethics, 2013, v. 27, n.6, p. 291-296.

FULGÊNCIO, C. A. A bioética de intervenção e a justiça social. Dissertação de mestrado em Bioética. Universidade de Brasília - UnB. Brasília, 2013.

GARRAFA, V.; PORTO, D. Intervention bioethics: a proposal for peripheral countries in a context of power and injustice. Bioethics, London, 2013, v. 17, n. 5/6, p. 399-415.

GARRAFA, V. Inclusão social no contexto político da bioética. Revista Brasileira de Bioética, Brasília, 2005, v. 1, n. 2, p. 22-32.

GARRAFA V. Bioética de Intervención; Imperialismo moral; Bioética y política. In: TEALDI, JC (org). Diccionario Latino-Americano de Bioética. Buenos Aires, 2006. GEORGESCU-ROEGEN, N. The Entropy Law and the Economic Process, Cambridge, MA: Harvard University Press, 1971. 
GOLDIM, J. R. Bioética complexa: uma abordagem abrangente para o processo de tomada de decisão. Revista da AMRIGS, 2009, v. 53, n. 1, p. 58-63.

GROSFOGUEL, R. Para descolonizar os estudos de economia política e os estudos póscoloniais: transmodernidade, pensamento de fronteira e colonialidade global. In: SANTOS, B.S.; MENESES, M. P. (orgs.). Epistemologias do Sul. São Paulo: Cortez, 2010, p.460.

GUATARRI, F. As três ecologias. 11 ed. Campinas: Papirus, 2001.

LEFF, E. Racionalidade ambiental: a reapropriação social da natureza. Ed civilização brasileira. Rio de Janeiro. 2006.

LEO, P. C. P. B. Fundamentos da bioética. III Congresso Brasileiro de Bioética e Saúde, São Paulo, 1995.

LEOPOLD, A. A Sand County Almanac. 1949. New York: Random House Publishing Group, 1953.

NASCIMENTO, W. F. Por uma vida descolonizada: Diálogos entre a Bioética de Intervenção e os estudos da colonialidade. Tese de doutorado, 2010

NASCIMENTO, W.F; MARTORELL, L . B. A bioética de intervenção em contextos descoloniais. Revista Brasileira de Bioética, Brasília, 2013; 21 (3), p. 423-31.

ORGANIZAÇÃO DAS NAÇÕES UNIDAS. Declaração da Conferência das Nações Unidas sobre o Meio Ambiente Humano. Disponível em: <http://www.onu.org.br〉. Acesso em 24 marc. 2016.

PASSMORE, John; GARDINER, Stephen. Environmentalism. In: GOODIN, Robert E.; PETTIT, Philip; POGGE, Thomas (Eds.). A Companion to Contemporary Political Philosophy. 2. ed. Oxford: Blackwell, 2007, v. 2, p. 572-589.

PESSINI, L. Problemas atuais de bioética. 2. ed., rev. e ampliada. São Paulo: Loyola, 1995.

PORTO, M. F. S; MARTINEZ-ALIER, J. Economic development axis and socioenvironmental conflicts generation in Brazil: challenges to sustainability and environmental justice. Ciênc. saúde coletiva, Rio de Janeiro, 2009, v.14, n. 6.

RANGEL, T. L. V. A problemática ambiental a partir de uma perspectiva da bioética: alinhando o discurso contemporâneo de preservação e o desenvolvimento sustentável. In: Âmbito Jurídico, Rio Grande, XVI, n. 117, out 2013. Disponível em: <http://www.ambitojuridico.com.br/site/index.php/?n_link=revista_artigos_leitura\&arti go_id=13201\&revista_caderno=6>. Acesso em marc 2016.

SCHRAMM, F. R. Ética ambiental e bioética global. Revista Redbioética/UNESCO, 2014, a. 5, v. 1, n. 9, p 71-78.

SCHUMACHER. E. F. O negócio é ser pequeno. São Paulo: Zahar, 1983.

TAYLOR, Paul. Respect for Nature: a theory of environmental ethics. Princeton: Princeton University Press, 1989.

UNESCO. Universal Draft Declaration on Bioethics and Human Rights. Paris, mimeo, 24 de junho 2005. UNESCO. UNESCO and Bioethics. Disponível em www.unesco.org/shs/bioethics. Acessado em 10 mar. 2016.

VUCETICH, J. A.; NELSON, M. P. Sustainability: Virtuous or vulgar? BioScience, 2010, v. 60, p. 539-44. 